\title{
Rice husk ash as filler in tread compounds to improve rolling resistance
}

\author{
Mônica Romero Santos Fernandes ${ }^{1,2 *}$, Ana Maria Furtado de Sousa ${ }^{2}$ and \\ Cristina Russi Guimarães Furtado²
}

\author{
${ }^{1}$ Lanxess Elastômeros do Brasil S.A., Duque de Caxias, RJ, Brazil \\ ${ }^{2}$ Instituto de Química, Universidade do Estado do Rio de Janeiro - UERJ, Rio de Janeiro, RJ, Brazil \\ *monicaromero.fernandes@gmail.com
}

\begin{abstract}
In the tire industry carbon black is being replaced by silica as a filler in recent due to the development of "green tires". Amorphous precipitated silica in combination with a silane coupling agent as a filler in tread compounds can result in fuel savings of $3 \%$ to $4 \%$ compared to a tire having treads made from compounds with carbon black. This means a $20 \%$ reduction of the rolling resistance and consequently lower greenhouse gas emissions. On the other hand, rice is one of the most important food crops generating around $22 \%$ in weight of husk during its milling, a material that is mainly used as fuel for energy generation, resulting in ash. Rice husk ash (RHA) contains over $70 \%$ of silica in amorphous form. In this paper we evaluated the effect of replacing carbon black with RHA in a basic tread formulation. Compounds mechanical, dynamic properties and morphology were analyzed.
\end{abstract}

Keywords: dynamic mechanical thermal analysis, mechanical properties, rice husk ash, rolling resistance, scanning electron microscopy.

\section{Introduction}

Carbon black is the most widely used filler in rubber compounds. However, in the tire industry it is being replaced by silica in recent decades due to the development of "green tires", which have lower rolling resistance as well as better abrasion resistance (durability) and wet grip (safety $)^{[1-4]}$.

As the tire deforms under the vehicle's weight during movement, a part of the mechanical energy available to turn the wheels is elastically stored while another part is dissipated as heat (hysteresis loss). This lost energy results in higher fuel consumption. Rolling resistance (RR) can be defined as the mechanical energy converted into heat by a tire moving over a unit of distance on the roadway. This lost energy is related to the viscoelastic properties of the rubber compounds, with a special role being played by the polymers and fillers used in the tread's compound ${ }^{[4,5]}$.

The use of amorphous precipitated silica in combination with a silane coupling agent as filler in tread compounds can result in fuel savings of approximately $3 \%$ to $4 \%$, compared to a tire having treads made from compounds with only carbon black. This means a $20 \%$ reduction of the rolling resistance and consequently lower greenhouse gas emissions. This has a considerable positive impact because vehicles are responsible for about $20 \%$ of $\mathrm{CO}_{2}$ emissions into the atmosphere ${ }^{[6-8]}$.

The retread industry is a technology follower of the tire industry, but even though aware of the importance of searching for new formulations, a significant portion of companies still mainly use carbon black in the tread recipe. This happens because the environmental and economic incentives of silica technology do not outweigh the higher cost of the process and the raw material involved. Therefore, one possible solution being evaluated is the use of mixtures of carbon black, silica and alternative fillers.

Rice is one of the most important food crops, with annual world production of approximately 670 million metric tons. During rice milling, around $22 \%$ by weight of rice husk is generated, a material that is mainly used as fuel for energy generation, resulting in ash. Rice husk ash (RHA) can contain over $70 \%$ silica in amorphous form, along with some amount of metallic impurities. Even though many applications are being studied for its use around the world, its disposal still represents an environmental issue ${ }^{[9-11]}$.

One of these applications is its use as filler in rubber compounds ${ }^{[1-13]}$. RHA can also be used as a raw material for precipitated silica production, by, for example, a process based on the reaction of silica with aqueous sodium hydroxide $(\mathrm{NaOH})$ in an autoclave, followed by precipitation with an acid, filtration, washings and drying stages ${ }^{[14,15]}$. There is already a tire company developing a similar process to prepare its own silica ${ }^{[16]}$.

The aim of this paper is to evaluate the effect of replacing a part of carbon black with RHA in a basic tread formulation. Tread rubber compounds were prepared in lab scale and their mechanical and dynamic properties were analyzed. The morphology of the compounds was also compared. Finally, RHA was characterized for its particle size, specific area and carbon and moisture contents in order to allow interpretation of the data obtained. 


\section{Materials and Methods}

\subsection{Materials}

The RHA used was supplied by Frenzel Indústria de Borrachas e Plásticos Ltda. The grade used was "super fine" (SF). It comes from a factory in the Brazilian state of Rio Grande do Sul, obtained by a fluidized bed process. Emulsion styrene butadiene rubber (Buna SE $1712 \mathrm{TE}$ ), composed of $76.5 \%$ butadiene and $23.5 \%$ styrene and extended with $37.5 \mathrm{phr}$ of a treated residual aromatic extract (TRAE); oil with low content of polycyclic aromatic hydrocarbons; and high cis-1.4 polybutadiene (Buna CB 24), obtained by solution polymerization using a Neodimiun based catalyst with cis content above $96 \%$, were supplied by Lanxess Elastômeros do Brasil. Carbon black N234 was produced by Cabot Brasil e Comércio S.A.; amorphous precipitated silica (Zeosil 1165MP) was supplied by Rhodia; and TRAE oil (Fluibrax Euro 40) was acquired from Petróleo Brasileiro S.A. Bis(3-ethoxysilylpropyl) tetrasulfide (TESPT) was obtained from Evonik Degussa Brasil Ltda. The other materials used were commonly used materials in the rubber industry.

\subsection{Experimental procedure}

A typical tread formulation with carbon black $(\mathrm{CB})$ was used as the basic reference. In order to evaluate the effect of rice husk ash (RHA) on the tread properties, compounds were prepared in which several parts of carbon black were replaced by equal amounts of RHA. Additionally, a compound using only commercial high dispersion silica (SIL) was also prepared to help interpretation of the analytical data. The formulations are shown in Table 1.

The compounds were prepared in a 2-liter tangential Banbury mixer with rotation of $80 \mathrm{rpm}$. Different mixture procedures were used, depending on the filler composition, as described below:

a) The compound containing only carbon black (CB) was prepared in a single stage, in which all components but the acceleration system were fed into the Banbury mixer at $80{ }^{\circ} \mathrm{C}$ and mixed for seven minutes. At the end of this period, the mixture was dumped.

b) Compounds with a mixture of carbon black and RHA were prepared in two stages. In the first one, all the ingredients, but the acceleration system, were added into the Banbury mixer at $80{ }^{\circ} \mathrm{C}$. Then the temperature was increased to $150{ }^{\circ} \mathrm{C}$ and maintained at that level for three minutes for the silanization reaction to occur. After this period, the mixture was dumped.

c) The compounds with $100 \%$ RHA and the other with $100 \%$ commercial silica were also prepared in two stages. In the first stage, all the ingredients, but the acceleration system, were added in the Banbury mixer at $80{ }^{\circ} \mathrm{C}$. The temperature was raised to $150{ }^{\circ} \mathrm{C}$ and maintained at this level for 2.5 minutes. Then the mixture was dumped and milled for two minutes in an open mill. The mixture obtained was returned to the Banbury mixer and heated for $2.5 \mathrm{~min}$, after which zinc oxide was added one minute before the material was dumped.

After all mixtures were dumped from the mixer and milled for 2 minutes and then allowed to rest at room temperature (around $25^{\circ} \mathrm{C}$ ) for at least 16 hours before being accelerated in an open mill.

\subsection{Characterization}

The carbon and moisture contents of the rice husk ash were determined by thermogravimetric analysis (TGA) (TA Q50 analyzer, from TA Instruments) with an initial temperature of $50{ }^{\circ} \mathrm{C}$, heating rate $10^{\circ} \mathrm{C} / \mathrm{min}$ until $800{ }^{\circ} \mathrm{C}$ with $\mathrm{N} 2$ atmosphere, followed by introduction of air flow until the temperature reached $950{ }^{\circ} \mathrm{C}$ with a ramp of $10^{\circ} \mathrm{C} / \mathrm{min}$.

The particle size distribution of the rice husk ash was analyzed by laser diffraction (Mastersizer 2000, Malvern Instruments Co. Ltd.).

The BET surface area was determined by using an accelerated surface area/porosimetry system (Micromeritics ASAPTM 2020).

Table 1. Tread rubber compounds in phr*.

\begin{tabular}{|c|c|c|c|c|c|c|}
\hline Component & $\mathbf{C B}$ & RHA 22.5 & RHA 45 & RHA 67.5 & RHA & SIL \\
\hline BUNA SE 1712 TE & 96.3 & 96.3 & 96.3 & 96.3 & 96.3 & 96.3 \\
\hline BUNA CB 24 & 30 & 30 & 30 & 30 & 30 & 30 \\
\hline Carbon Black (N 234) & 90 & 67.5 & 45.0 & 22.5 & 7.0 & 7.0 \\
\hline RHA (SF) & - & 22.5 & 45.0 & 67.5 & 90.0 & - \\
\hline Silane (Si-69) & - & 1.8 & 3.6 & 1.8 & 7.2 & 7.2 \\
\hline Silica (Zeosil 1165MP) & - & - & - & - & - & 90.0 \\
\hline Sulfur & 2.0 & 2.0 & 2.0 & 2.0 & 2.0 & 2.0 \\
\hline Zinc oxide & 3.0 & 3.0 & 3.0 & 3.0 & 3.0 & 3.0 \\
\hline Stearic acid & 1.0 & 1.0 & 1.0 & 1.0 & 1.0 & 1.0 \\
\hline TBBS & 1.3 & 1.3 & 1.3 & 1.3 & 1.3 & 1.3 \\
\hline DPG & 0.3 & 2.0 & 2.0 & 2.0 & 2.0 & 2.0 \\
\hline Vulkanox 4020/LG & 2.0 & 2.0 & 2.0 & 2.0 & 2.0 & 2.0 \\
\hline Vulkanox HS/LG & 2.0 & 2.0 & 2.0 & 2.0 & 2.0 & 2.0 \\
\hline Oil (Fluibrax Euro 40) & 11.2 & 11.2 & 11.2 & 11.2 & 11.2 & 11.2 \\
\hline Wax (Antilux 653) & 2.0 & 2.0 & 2.0 & 2.0 & 2.0 & 2.0 \\
\hline Process additive (Aflux 37) & - & - & - & - & 2.0 & 2.0 \\
\hline
\end{tabular}

*Parts per hundred rubber. 
The Mooney viscosities of the crude rubber and compound (ML1+4) were determined following the ASTM D1646 method at $100{ }^{\circ} \mathrm{C}$ in an Alpha Technologies viscometer (MV 2000).

Rheometry was determined in an MDR rheometer from Alpha Technologies (MDR 2000P), with $100 \mathrm{cpm}$ frequency, $0.5^{\circ}$, temperature of $160^{\circ} \mathrm{C}$, during 30 minutes, for measurement of t'90.

Analysis of the tensile properties followed the ASTM D412 method, using an Instron 5581 tensiometer.

Shore A hardness was measured following the ASTM D2240 method in a Bareiss durometer while rebound was determined following the ASTM D1054 method in a Zwick \& Co KG device. Abrasion resistance was measured following the DIN53516 method using a Maqtest device.

Dynamic tests were conduct in a dynamical mechanical analyzer (DMA 50N 01 Db-METRAVIB) in tensile mode. The temperature dependence (temperature sweep) of the loss factor (tan delta) and the storage modulus ( $\left.\mathrm{G}^{\prime}\right)$ were measured in the temperature range from $-60^{\circ} \mathrm{C}$ to $80^{\circ} \mathrm{C}$, at a heating rate of $3{ }^{\circ} \mathrm{C} / \mathrm{min}$, frequency of $10 \mathrm{~Hz}$ and dynamic strain of $1 \%$.

The Payne effect was evaluated by strain dependence of the storage modulus (G') using the DMA at $1 \mathrm{~Hz}$ and $60^{\circ}$.

\section{Results and Discussions}

\subsection{Characterization of the rice husk ash}

The RHA sample received from Frenzel presented a carbon content of $12.4 \%$ as determined by TGA (Figure 1). This carbon content was considered high since the material was produced with a fluidized process. It might be related to the presence of potassium in the husks, which acts at the melted surface, causing fixation of carbon in the ash.

The RHA average particle size was determined by laser diffraction in a Martersizer 2000 with a mean value of 6.97 microns and a standard deviation of 0.137 . The BET specific area was $81 \mathrm{~m}^{2} / \mathrm{g}$.

\subsection{Properties of the compounds}

Table 2 shows the results of the properties determined for the formulations.

A reduction can be observed in reinforcement as carbon black was replaced by the RHA in the tread formulation. This fact can also be observed through comparison between the RHA and SIL compounds. This behavior can be explained by the higher particle size of RHA and consequently the smaller specific surface area presented by this ash $\left(81 \mathrm{~m}^{2} / \mathrm{g}\right)$ in relation to the other fillers used: carbon black $\left(120 \mathrm{~m}^{2} / \mathrm{g}\right)$

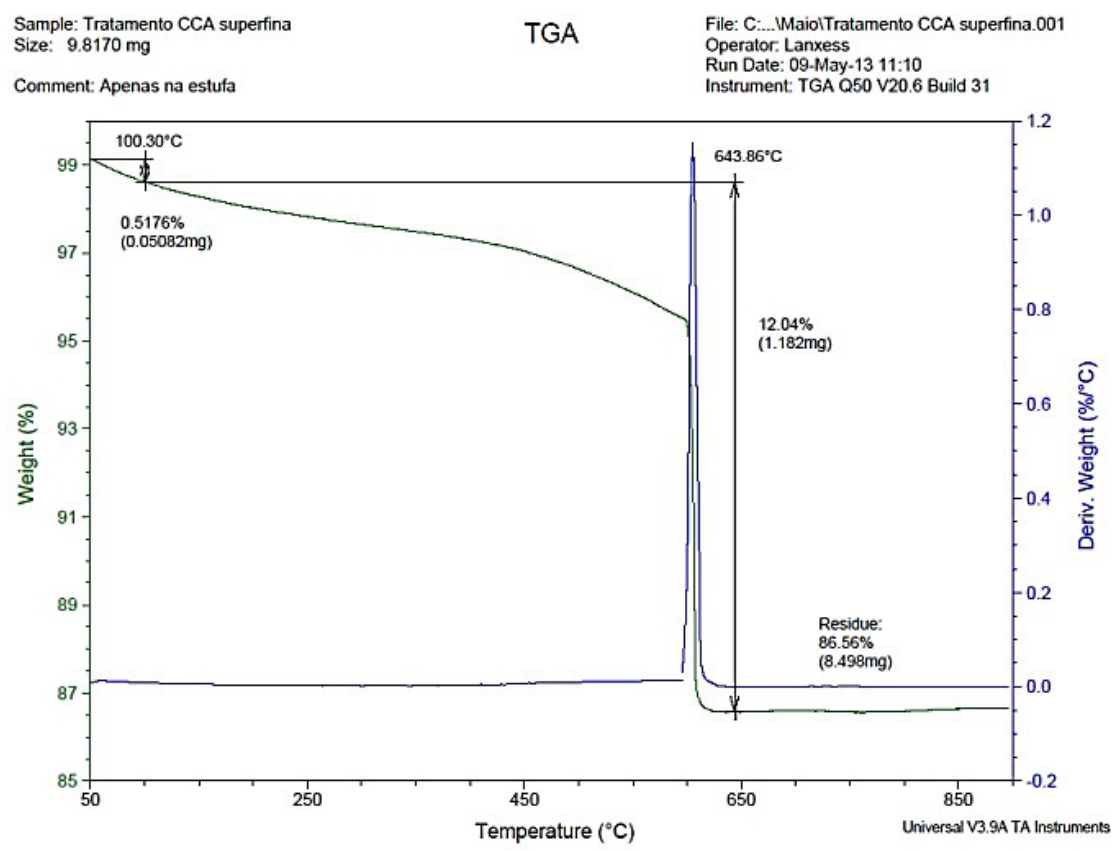

Figure 1. TGA analysis of SF RHA used in this paper.

Table 2. Compounds properties.

\begin{tabular}{ccccccc}
\hline Property & CB & RHA 22.5 & RHA 45 & RHA 67.5 & RHA & SIL \\
\hline Mooney viscosity, MML (1+4) & 90 & 71 & 82 & 84 & 61 & 87 \\
300\% Modulus (MPa) & 13.7 & 15.4 & 12.5 & - & - & 15.6 \\
Tensile strenght (MPa) & 21.3 & 22.2 & 13.1 & 9.0 & 8.0 & 21.8 \\
Elongation (\%) & 454 & 408 & 318 & 247 & 227 & 376 \\
Hardness (Shore A) & 71 & 64 & 60 & 56 & 57 & 63 \\
Tear strenght, (kN/m) & 37 & 35 & 29 & 24 & 25 & 39 \\
\hline
\end{tabular}


and high dispersion silica $\left(170 \mathrm{~m}^{2} / \mathrm{g}\right)$. According to the literature, the classification of fillers into non-reinforcing, semi-reinforcing or reinforcing is strongly dependent on the size of the particles, with 6 microns being the primary particle size at the limit of semi-reinforcing and non-reinforcing fillers ${ }^{[7]}$. In this way, this ash, with particle size near 7 microns, can be considered a non-reinforcing filler.

In relation to the viscosity, the decrease in the compound Mooney viscosity with increasing RHA content was probably also related to this lower specific area, which is associated with lower bound rubber content, reducing the contribution of the in-rubber-structure's effect to the elastic modulus of the compound ${ }^{[17]}$.

\subsection{Morphology of the compounds}

The SEM analysis of the tensile fracture surface is a technique which allows observing the filler dispersion in a rubber compound. Figures 2-4 show, respectively, the images of RHA, RHA 45 and SIL compounds.

From Figures $2 \mathrm{a}$ and $3 \mathrm{a}$, it is possible to verify the large size and broad distribution of the RHA particles,
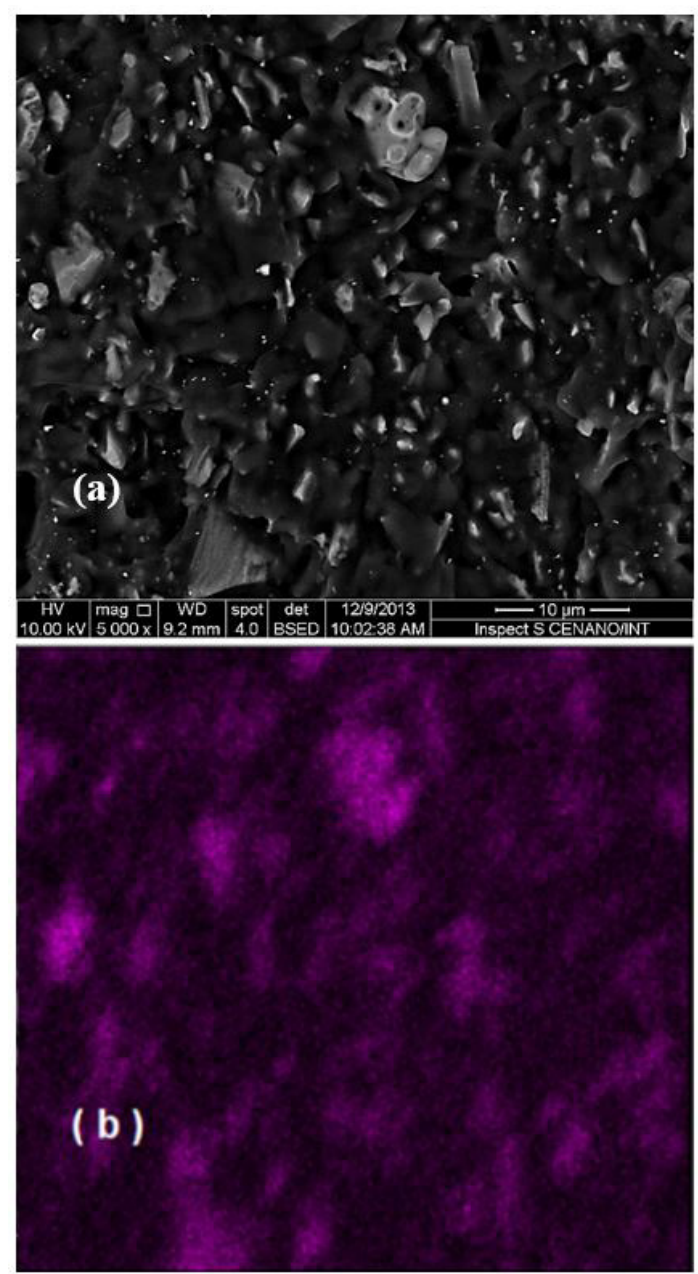

Figure 2. (a) SEM photomicrograph of the tensile fracture surface of RHA; (b) EDS analysis of RHA. which is confirmed by EDS analysis (Figures $2 b$ and $3 b$ ). The particle size of RHA is in accordance with the results obtained by laser refraction. The presence of carbon black cannot be observed due to the fact that its particles have nano dimensions, which are not observable with SEM resolution.

According to Figure 4, as expected, the silica aggregates are not visible from this technique. Only some small agglomerates are visible, which may be present even with the use of silane due to incomplete coverage of all particle surfaces. The identification of the small white points was carried out with EDS to identify the elements present in them, which confirmed the concentration of silicon.

\subsection{Rebound and abrasion resistance evaluation}

Figure 5 shows the results of rebound and DIN abrasion of the compounds. It can be observed the rebound increases as the RHA content increased in the formulation. As the filler's specific surface area is reduced, a reduction of the filler-filler interaction can be expected, with reduction of energy loss, resulting in a more elastic performance of the material[ ${ }^{[7]}$. Due to the same reason, a reduction of the bound rubber can also be expected, which also contributes to the elastic response, as it acts as an immobilized rubber. The abrasion resistance is related to the rupture of small

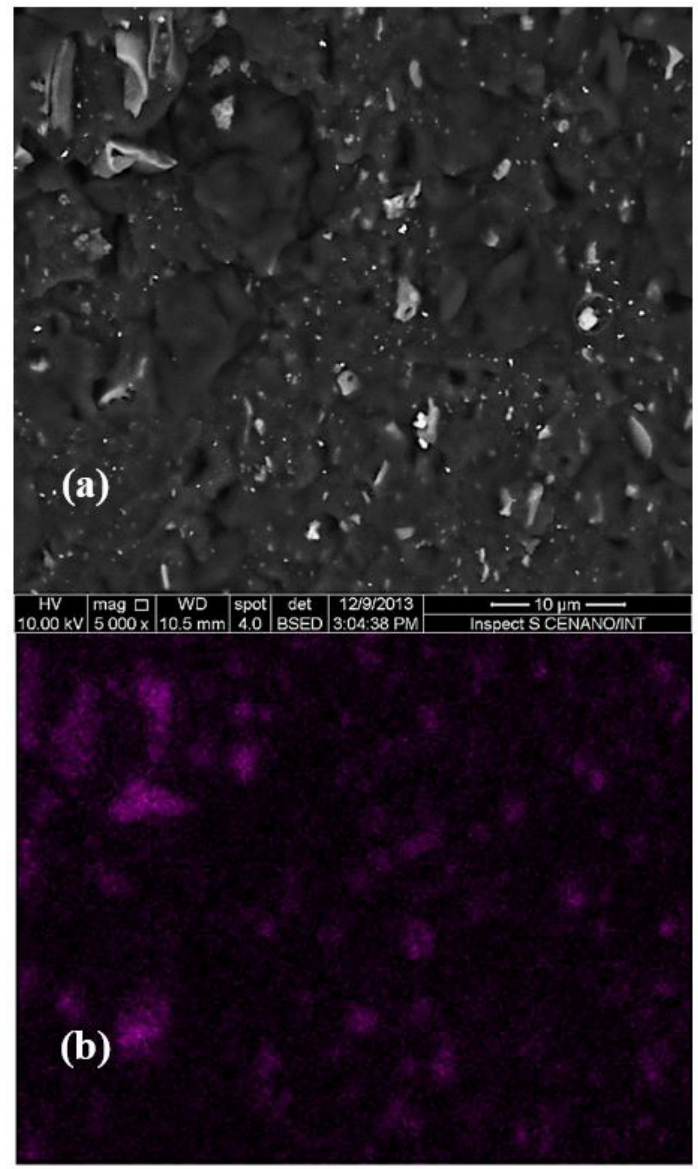

Figure 3. (a) SEM photomicrograph of the tensile fracture surface of RHA45; (b) EDS analysis of RHA45. 
particles of the compound under the action of frictional forces, when sliding takes place between the compound surface and a substrate. It is normal to expect a compound containing fillers with large particle size to present a lower filler-polymer interaction, leading to lower cohesive forces and the removal of a significant amount of material. Moreover, in the case of silica-silane as filler, the formation of the covalent link between the filler and the polymer plays an important role in abrasion resistance, being reduced in this case due

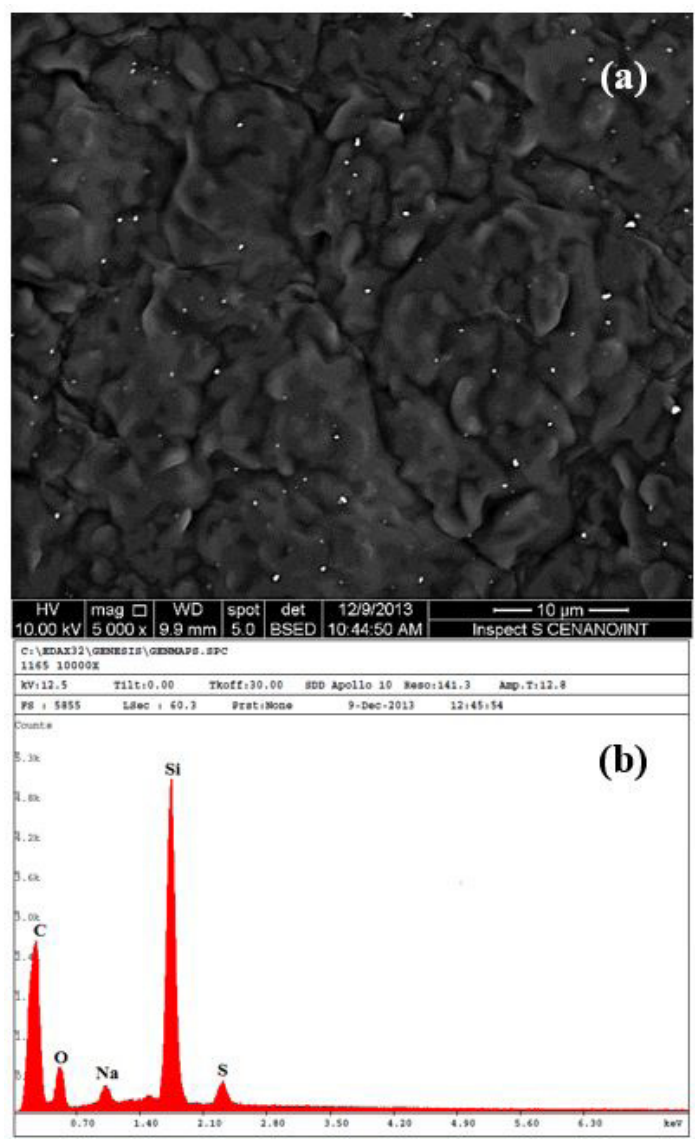

Figure 4. (a) SEM photomicrographs of the tensile fracture surface of SIL; (b) Punctual EDS analysis of one of the white points identified in the image.

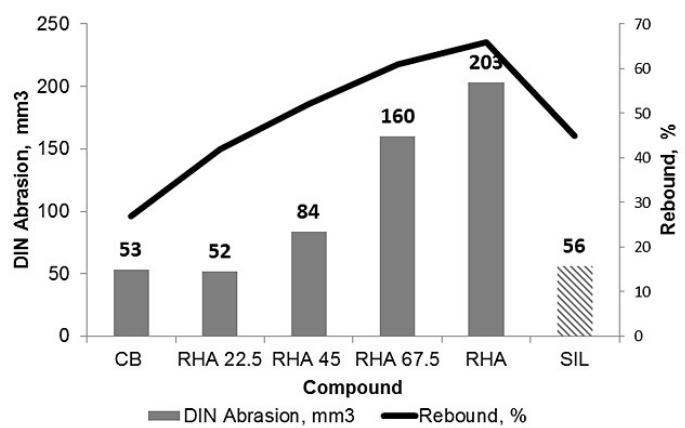

Figure 5. Results of DIN abrasion and rebound from the studied recipes. to lower specific area and the presence of a relatively high quantity of carbon $(12 \%)$ on the surface. Unfortunately, the surface activity of the RHA and commercial silica could not be compared by the available techniques used in these experiments.

\subsection{Dynamic mechanical analysis of the compounds' vulcanizates}

Dynamic mechanical analysis is usually used to evaluate tire performance. It is well recognized that high values of tan delta at $0{ }^{\circ} \mathrm{C}$ mean better wet grip whereas low values of $\tan$ delta at $60^{\circ} \mathrm{C}$ are correlated with lower rolling resistance (lower fuel consumption) ${ }^{[4]}$.

Figure 6 presents the temperature dependence of tan delta in the range of 50 to $70^{\circ} \mathrm{C}$ for the prepared compounds. It can be noted that silica significantly reduces the value of tan delta at $60{ }^{\circ} \mathrm{C}$ in relation to carbon black in the compounds, as already stated in Michelin's patent, indicating a reduction of hysteresis, resulting in low fuel consumption ${ }^{[3]}$. Similarly, the compounds with RHA also presented a reduction in tan delta values at $60{ }^{\circ} \mathrm{C}$. This result is produced by a lower filler-filler interaction resulting from lower specific surface area of RHA, with formation of a weak filler network. In a rolling tire, this breakdown of the filler network during deformation would result in dissipation of energy, creating hysteresis and therefore increased rolling resistance. So, the weak filler network results in a low dissipation of energy, which provides more elastic performance of the compound, with a lower tan delta and lower fuel consumption. Lower values of tan delta for RHA in relation to commercial silica can be observed, which is also related to a weaker filler network. As Zeosil 1165 has a higher specific area, the interaction between filler particles is more intense, resulting in stronger filler-filler interaction.

The Payne effect, the variation in modulus observed at small deformation amplitude during strain sweep test, is widely used to evaluate the filler network in rubber compounds, being related to filler dispersion as well as the filler-filler interaction. The small delta G'values (difference between low strain G' and high strain G') are related to a weaker filler-filler interaction and consequently lower heat generation during deformation of the treads during rolling, and are expected as an indication of good dispersion (better polymer-filler interaction) and better performance in

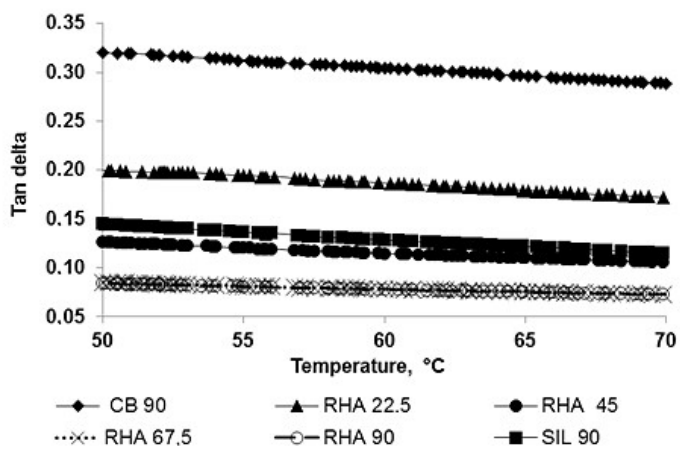

Figure 6. Tan delta versus temperature for the range of 50 to $70^{\circ} \mathrm{C}$. 


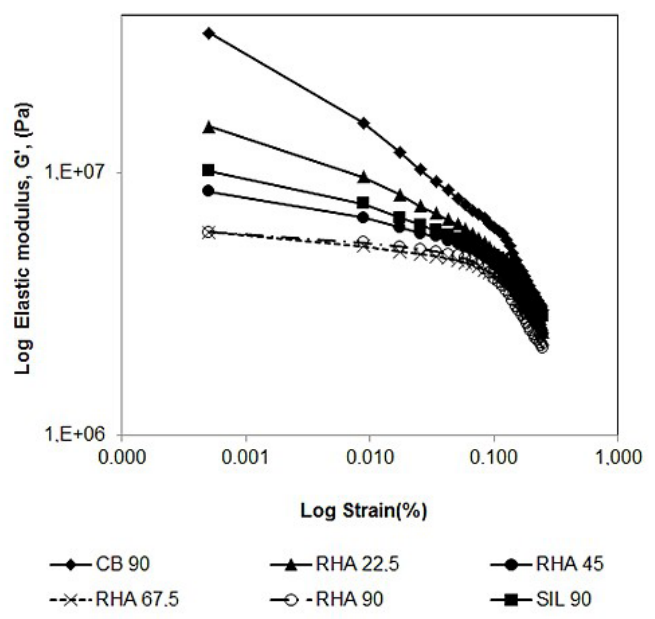

Figure 7. G' versus strain test at $60^{\circ} \mathrm{C}$ - Payne Effect.

relation to fuel economy. A clear tendency of this behavior can be observed in Figure 7 as the content of RHA increases in the prepared compounds. The weaker filler-filler interactions observed with the use of RHA makes breakage of the network easier when the compound is submitted to low strains. It can also be observed that the delta G' value for the compound prepared with commercial silica is higher than the one for the sample prepared with $100 \%$ RHA, which is related to the higher specific area and stronger filler-filler interaction in this compound.

\section{Conclusions}

The results obtained allow concluding that the use of RHA in tread compounds significantly reduces the reinforcement in relation to commonly used fillers: carbon black and silica. This can be observed by reduction of tensile strength, elongation and tear resistance. It is well known that reinforcement is related to the surface area of the filler and it was verified that RHA sample used had a much lower surface area in comparison with the other fillers tested.

Abrasion resistance is a critical property for tire and retread segments and it was also verified that RHA decreases this property. So, based on the data obtained, it can be concluded that this type of RHA acted as non-reinforced filler and should not be considered as a substitute for silica in a tread formulation, even with good indications of rolling resistance reduction (lower tan delta at $60{ }^{\circ} \mathrm{C}$ ).

The formulation with $25 \%$ replacement of carbon black by RHA showed satisfactory physical properties and abrasion resistance, also providing reduced rolling resistance (low tan delta at $60^{\circ} \mathrm{C}$ ), which can justify a more complete evaluation of this compound, including outside tests for abrasion evaluation.

\section{Acknowledgements}

We would like to thank Lanxess Elastomeros do Brasil S.A. for making all the tests possible, all suppliers for donating samples and Instituto Nacional de Tecnologia INT for the support in MEV analysis.

\section{References}

1. Eirich, F. R., Erman, B., \& Mark, E. J. (2005). The science and technology of rubber. New York: Elsevier.

2. Li, Y., Han, B., Liu, L., Zhang, F., Zhang, L., Wen, S., Lu, Y., Yang, H., \& Shen, J. (2013). Surface modification of silica by two-step method and properties of solution styrene rubber (SSBR) nanocomposites fillied with modified silica. Composites Science and Technology, 88, 69-73. http://dx.doi. org/10.1016/j.compscitech.2013.08.029.

3. Rauline, R. (1993). US Patent 5,227,425. Retrieved in 23 December 2015, from http://www.google.com/patents/ US5227425

4. Fernandes, M., \& Santos, N. (2013). SBR em solución para neumaticos de alto rendimento. In XII Jornadas Latinoamericanas de Tecnologia Del Caucho. Buenos Aires: SLT Caucho. Retrieved in 23 December 2015, from http://www.sltcaucho. org/jornadas2013/trabajos-tecnicos/\#inline_content-conferencias

5. Transportation Research Board. (2006). Tires and passenger vehicle fuel economy (Special Report, vol. 286). Washington: National Research Council of the National Academies. Retrieved in 23 December 2015, from http://onlinepubs.trb. org/onlinepubs/sr/sr286.pdf

6. Dierkes, W. (2005). Economic mixing of silica-rubber compounds Interaction between the chemistry of the silica-silane reaction and the physics of mixing (Doctoral thesis). University of Twente, Enschede.

7. Mihara, S. (2009). Reactive processing of silica-reinforced tire rubber, new insight into the time- and temperature-dependence of silica rubber interaction mixing (Doctoral thesis). University of Twente, Enschede.

8. Dierkes, W. K, Noordermeer, J. W. M. (2012). Annual showcase. Tire Technology International, 14-18.

9. Pouey, M. T. F. (2006). Beneficiamento da cinza da casca de arroz residual com vistas à produção de cimento composto el ou pozolânico (Master's dissertation). Universidade Federal do Rio Grande do Sul, Porto Alegre.

10. Ismail, H., Nasaruddin, M. N., \& Rozman, H. D. (1999). The effect of multifunctional additive in white rice husk ash filled natural rubber compounds. European Polymer Journal, 35(8), 1429-1437. http://dx.doi.org/10.1016/S0014-3057(98)00223-7.

11. Chandrasekhar, S., Pramada, P. N., \& Praveen, L. (2005). Effect of organic acid treatment on the properties of rice husk silica. Journal of Materials Science, 40(24), 6535-6544. http:// dx.doi.org/10.1007/s10853-005-1816-z.

12. Costa, H. M., Furtado, C. R. G., Nunes, R. C. R., \& Visconte, L. L. Y. (2001). Rice-husk-ash-filled natural rubber. ii. partial replacement of commercial fillers and the effect on the vulcanization process. Journal of Applied Polymer Science, 83, 2485-2493. http://dx.doi.org/10.1002/app.11514.

13. Ismail, H., Nasaruddin, M. N., \& Ishiaku, U. S. (1999). White rice husk ash filled natural rubber compounds: the effect of multifunctional additive and silane coupling agents. Polymer Testing, 18(4), 287-298. http://dx.doi.org/10.1016/S01429418(98)00030-0.

14. Kalapathy, U., Proctor, A., \& Shultz, J. (2000). A simple method for production of pure silica from rice hull ash. Bioresource Technology, 72(3), 257-262. http://dx.doi.org/10.1016/S09608524(99)00127-3.

15. Furtado, C., Mansur, C., Sousa, A. M., \& Visconte, L. (2009). Silica sol obtaained from rice husk ash. Chemistry \& Chemistry Technology, 3, 331-336. Retrieved in 23 December 2015, from ena.lp.edu.ua:8080/handle/ntb/3307

16. Pirelli. (2012, June 18). Pirelli apresenta na Rio +20 projetos com o ministério do meio ambiente italiano e o Estado de São Paulo, visando reduzir o impacto ambiental na produção e uso 
de pneus. Retrieved in 23 December 2015, from http://www. pirelli.com/tyre/br/pt/news/2012/06/18/pirelli-apresenta-nario-20-projetos-com-o-ministerio-do-meio-ambiente-italianoe-o-estado-de-sao-paulo-visando-reduzir-o-impacto-ambientalna-producao-e-uso-de-pneus

17. Fröhlich, J., Niedermeier, W., \& Luginsland, H.-D. (2005). The effect of filler-filler and filler-elastomer interaction on rubber reinforcement. Composites. Part A, Applied Science and Manufacturing, 36(4), 449-460. http://dx.doi.org/10.1016/j. compositesa.2004.10.004.

Received: Dec. 23, 2015

Revised: Apr. 21, 2016

Accepted: May 17, 2016 